\title{
From Discord to Concord and Back Again (Managing the Formation, Transformation, and Fission of Organizational Culture)
}

\author{
Armen E. Petrosyan \\ Institute for Business Consulting, \\ Tver, Russia
}

moi@myabode.ru

\begin{abstract}
By means of theoretical analysis based on the results of previous research, and the relevant historical and factual material, the author outlines a new theory of formation, transformation, and fission of organizational culture. The mechanism that consolidates organizational culture (selection of "right" persons; adjustment to the common cause; and people's accommodation with each other), the toolkit for renewing it (involvement of the key bearers of the culture to be introduced; elimination of those inconsistent with it; and translation of the proclaimed values to the "pliant mass" ready to get engaged in changes) as well as the nature of cultural ruptures in organizations and the ways out are brought into relief. The paper promotes a better understanding of the dynamics of organizational culture and gives an access to more efficient instruments to manage it.
\end{abstract}

Keywords: organizational culture, mechanism of consolidation, pattern of transformation, cultural split, management of culture

\section{Introduction}

Elliott Jacques who was the first to thoroughly explore culture as applied to organizations stated that "the culture of the factory is its customary and traditional way of thinking and of doing things, which is shared to a greater or lesser degree by all its members, and which new members must learn, and at least partially accept" $[1$, p. 251]. He emphasized the role of values as a prerequisite and moving force in establishing efficient interpersonal and professional relations. It was obvious to him that without shared values, workers could scarcely act together as a single whole.

At about the same time, to the same conclusions, albeit from another standpoint, came Talcott Parsons. According to him, any organization should get integrated so as to appear as a collective unit [2, p. 20]. And the force joining them is common values they keep to. "Where roles are differentiated," Parsons observes, "the sharing of values becomes an essential condition of integration of the system." For an organization to act effectively and achieve the results it seeks, "there must be, to some degree and on some level, a unitary system of institutionalized values, in this aspect a common culture." Only due to that, a group of people "constitute a single 
collectivity" [3, pp. 167, 169]. The culture they adopt communicates meaningfulness to the goals being pursued, and stability, to the patterns of their doing.

More than six decades elapsed since. A heap of works - both conceptual and empirical - devoted to organizational culture saw the light. Diverse approaches to it emerged aplenty. However, all they still rotate on the axis of values.

Simona Giorgi and her colleagues "revealed five prominent models of culture used by organization scholars: as values, stories, frames, toolkits, and categories". However, as they stress, these models "stand on unequal footing." Values and toolkits constitute the core round which the rest of them run [4, pp. 4, 20]. Indeed, "stories", "frames", and "categories" are secondary. But so are "toolkits" as well. They retain a cultural meaning, that is, turn into a part of culture, exactly to the extent they are stamped with values.

The exponents of "toolkits" treat culture as a reservoir of opportunities people possess or available resources and instruments, and pass it through the lens of not so much things or their importance for people as practical actions. The metaphor "toolkit" is called upon to shift "attention away from values as the driving force of behavior to bits and pieces of culture that can be differently assembled, opening up the possibility of a variety of outcomes, even given the same values." But it is impossible to put an end to a phenomenon by evading it. The examples the authors adduce demonstrate, contrary to their intent, that one concept is merely replaced with another. So, they insist that, despite health is an undoubted value for most people, their real actions are drawn on wonted repertoires and frequently cause harm to health $(4$, pp. $13-14)$. But does this mean that instruments of behavior are quite independent of values?

Sure, sometimes health is put at risk, but not because it is occulted by habitual doing. As a value it still guides the behavior. However, no value can be an isolated and, all the more, a single entity. Each is surrounded by other values which modify its role and restrain its influence. Moreover, values always constitute a hierarchy with an essential subordination of its elements. Some of them seeming to be most important turn out less significant when confronted with stronger ones. Thus, health may be pushed to the sidelines if it deprives people of pleasure or prejudice their status when pleasure or status is of higher priority to them than health.

Of course, nobody devises all the actions he undertakes, from scratch. In most cases, ready-to-use patterns are employed. But which of them is chosen and in what combination, depends just on the values one follows. Any instrument must be not only efficient but also acceptable. And consequently, it cannot be value-free.

A degree of unity in value orientations is the main and indispensable condition of integration and joining of efforts. Organizational meanings and priorities should be in tune with people's personal attitudes and preferences. Sure, not all and not to the same extent put up with the values of their organization, but that the values must be accepted at least by its active backbone is beyond doubt. Meanwhile, this engenders a difficulty which most researchers not only disregard but even do not notice.

How are shared values possible if organizations comprise people with very diverse attitudes, social and life experiences, and personal likings? Before fusing 
into a collective, workers have, for the most part, no notion of each other and of what are their fellows' values. An association of those with more or less similar cultural backgrounds may look to be quite realistic, since they are primordially guided by kindred priorities. But the probability of that tens, hundreds, and thousands of "suitable" persons turn up at the same time in the same place by accident, is lost in the noise, while divergences and, all the more, inconsistencies in values seem to make any joint activity of their bearers almost infeasible. And yet, organizations with so unlike members are in abundance, and they contrive to maintain the unity of their cultures. That is why the mechanism of transition from the discord of variegated societal values to a harmony in an integral organizational culture as well as its transmutation and splitting appears to be the pivot without which no satisfactory theory of organization can be built.

What do organizations owe their cultural uniformity to? How do they get it? What does lead to metamorphoses in organizational culture? Why, despite essential changes in values, does it ensure their commonality? When is a culture threatened with disintegration? And is its breakup into antagonistic pieces preventable? By answering these questions, the author reveals the key mechanisms in the dynamics of organizational culture and suggests efficient measures for managing it.

\section{The Making of Cultural Unity}

People do not grow up in an organization or join it after adopting its culture. One may import a cultural "baggage" essentially differing from that of its other members. This urges on some researchers to deny organizations, particularly multi-national, to have common values, or at least to acknowledge only their minor part in ordering the organizational life. "What holds a successful multinational together," Hofstede asserts, "are shared practices, not, as the 'corporate culture' hype of the early 1980s wanted it, shared values" [5, p. 1360]. The problem gets moved aside. However, that is not an actual solution to, but, rather, an escape from it.

\subsection{The culture of Founder(s) the Ground for Homogeneity}

Though sometimes are found relatively small affinity groups, in most cases there are really no societal values common to all workers. Nevertheless, it is beyond doubt that the majority are guided by similar or related business priorities. Should it be otherwise organizational culture would lose its practical meaning. And the cultural cement fastening together the parts of an organization and creating in it a favorable milieu for efficient joint activity would disappear as well.

The fusion of individual business cultures in an organization implies some initial core round which they cohere into a single whole and are put in order. Every entrepreneur, according to Edgar Schein, has clear and strong convictions as to what and how to do which ensue from his previous experience and personal preferences. By combining them with his views on the world and the mission the organization established by him is to perform, he sets, as the founder, the main tendency of its future culture $[6, \mathrm{p} .225]$. In the course of development, the culture acquires more 
comprehensive contents and gradually absorbs the compatible business values of other notable members. So the cultural dominant of the organization gets crystallized. It is always appreciable and manifests itself distinctly even if individual workers or their groups do not emphasize its role or keep to priorities somewhat different from each other.

A good illustration of this is the early history of the accounting firm "Arthur Andersen." At the very beginning of its activity, in 1915, it turned out in a rather awkward situation. Its client, a railway company, in order to improve the financial statements deferred relatively large charges to be taken into account as current expenses and, thereby, essentially distorted the data. Andersen required the statements to reflect the facts and drew up a report in which the costs had been presented according to their true nature, while the head of "railroaders" demanded from him to "correct" the report. To this, Andersen answered that there was not enough money in Chicago to make him do it. Despite the hard time and the fact that the firm was just getting on its feet, and every client was worth its weight in gold, he preferred to lose the client than betray his own values [7, pp. $19-20]$. The principle embedded by him in the business philosophy of the firm got implanted there and continued to work many decades on.

That the culture of an organization imbibes and assimilates the business orientations of its head receives also empirical backing. Thus, it has been found that "organizational culture values are, at least to some extent, a reflection of the CEO's personality." Say, those reluctant to get involved in new undertakings are commonly surrounded by employees who view "their organizations' culture as characterized by higher levels of hierarchical values." And they together "foster cultures that encourage stability and control of operations" [8, pp. 133 - 134]. No wonder: as the core, so the fruit.

But how the basic business values are transmitted to workers and inculcated in them?

It is the primary selection that underlies the relative homogeneity of organizational culture. The placing of personnel appears to be a rather rigorous procedure which not everyone can pass. So, in order to hire 3000 workers for an assembly plant in Kentucky, "Toyota" had screened out and rejected nearly 100 thousand applicants [9, p. XVI]. Candidates for a vacancy go through a sieve of quite exacting requirements that are not at all of formal nature, but step far beyond the limits of job descriptions.

No less, and at times more, significant is the individual's conformity with the demands on him as a personality, his ability to fit in with the cultural milieu of the organization [10]. The model of "ideal" worker implies him to be not merely a qualified specialist ready to do the job up to the mark (meet the high standards of performance), but first and foremost, to subordinate himself to the common cause, the satisfaction of his own ambitions being put on the back burner. But this means just a knack of getting built into the culture which underprops the common cause. Consequently, winning the vacancy presupposes outstripping the contenders most of all in cultural and personality accordance with the organization's central values. 
Hence, already at the stage of admission, is done the most for the worker to be not unconcerned about them.

However, errors happen on the part of both those who make selection and candidates for jobs. Some of employers neglect their duties or incorrectly assess the aptitudes of applicants, and the latter turn out to be alien to the values of the organizations they join. Likewise, an applicant himself may make a faulty choice through underestimating the disparity between the organization's and his own cultural preferences, defying it, or going along with alien rules because of the despair (acute need) he is gripped by. In these cases, most often either the organization gets rid of the unsuitable worker or the worker himself, on understanding that has got a wrong number, rather quickly quits his job.

The empirical study of the correlation between employee's perceptions of and preferences for organizational culture and his commitment to the organization and intention to stay with it has shown that "people adapt best when there is a good person - environment $(\mathrm{P}-\mathrm{E})$ fit." And contrariwise, the deviation of the cultural realities of the organization from the expectations most likely brings to the slackening in their commitment to it and readiness to remain a part of the collective [11, pp. 458 - 459]. However, it is known that novices who do not leave the organization during first several months usually stay there for long. Thus, a member not willing to accept cultural values of his organization gets "culled" by a kind of natural selection. That restrains, from the very outset, the sources of remonstrance and opposition due to which an organization might run a danger of rupture.

\subsection{Adjustment to the Tasks, and Reciprocation}

It would be naïve to believe that those remaining in an organization primordially and totally share its values. Many of newcomers evince virtually no opposition not because are overjoyed at them. Rather, despite some skepticism maintained by workers about the organizational culture, it arouses in them no strong disapproval; or they attach small importance to the "inacceptable" values and, therefore, the dissensions do not hinder them in joint activity.

The common cause expresses not only the interests of the organization but, to some extent, also those of the workers, providing them with opportunities of earnings, self-fulfillment, professional communication, etc. This increases their personal involvement and reinforces commitment to the organization and selfdevotion in the course of work [12, pp. $147-148]$. In the issue, the readiness for certain sacrifices, losses, and compromises for retention and increase of what has been acquired thank to the collective rises. Respectively, they put up with the "demands" (values, principles, and norms) which at first seem to them not quite opportune and reasonable. Moreover, when nothing of the kind does occur, all sorts of explanations mitigating the contradictions between their personal attitudes and the "doubtful" elements of the organizational culture are devised. As a result, people even within the same unit or work group - sometimes very differently treat the meaning of cultural entities. 
For instance, the policy of constant improvements is supposed to support the creative approach to the tasks being performed, and some autonomy in decisionmaking. But not all of those working in an organization where it has been successfully introduced believe that its main advantage is the freedom of action it provides with. Some find this policy to give them an opportunity for selfdevelopment, while others associate it with the stability of the collective they belong to. That is to say, people attach to the same elements of culture not identical meaning, since pass them through the lens of their own expectations and preferences. The only thing which creates an affinity between these interpretations is that they allow employees to regard a cultural entity as something meeting their needs.

Any organizational novelty should fit in with the notions and expectations of workers. Otherwise it would scarcely function as devised. The Toyota way, including the policy of continuous improvement, "is most often viewed as a set of tools to remove 'waste' from processes" [13, p. 3682]. And just for that very reason, the attempts to implant this production system in another cultural ground ordinarily end with failure. It is not a mere formula, a magic spell which by itself is able to transform the life of an organization, but, rather, a "clod" of culture; not only knowledge of an instrument and skill in handling it but also - what is much more important - an ability to understand which of instruments, when, and how should be employed. It needs "to ensure that the tools implemented fit the organization and support its people while achieving the objectives they were designed for" [13, p.3696]. Toyota way is a culture supported by a toolkit, not a set of instruments as an appendage to that culture. For an instrument to function, people must communicate to it their own sense so as to turn it into a part of their inside cultural world.

When the demands made on a worker evidently help him in fulfilling his task they, though not accepted totally, are taken in with understanding and, in any case, are not dismissed out of hand. As workers get "built" into the common cause and "appropriate" it, that is to say, make it their "own," they more and more accustom themselves to the organizational culture as promoting the common cause and, thereby, answering their own interests. At that, people's attitudes and preferences get geared to the organizational culture and corrected so as to eliminate obvious, outrageous divergences and discrepancies. Thus a single "strategic" orientation arises which, for all the diversity of societal cultures the workers have imbibed, sets the integral "vector" of the organizational culture, unifying and "aligning," to some extent, their strivings and valuations.

Joint activity in the course of achieving the common goals not merely gives workers an opportunity to rally round it but also allows them to pool their efforts [14, p. 282]. In the issue, they come closer and get adapted to each other, while their notions of what is done, and mindsets, however diverse at the outset, begin to overlap and sometimes even coincide. This imparts a certain measure of 
homogeneity to the business cultures of individual employees thank to what they behave not only as a single whole, but frequently undertake steps to the same template and together oppose abrupt changes. Not in vain, many executives complain that employees often come out with very similar ideas, for instance, during brainstorms. This occurs even in organizations encouraging creativity and innovations, such as "Toyota" [15].

In the course of communication and joint working, some rectification, reconciliation, and mutual adjustment of personal attitudes and preferences are made. The crucial role of meetings "in employee socialization, relationship building and shaping of the culture" comes to be more evident. Inter alia, "they reinforce formal and informal reporting structures, and provide clues about organizational values" [16, p. 18].Within the bounds of possibility, workers find "tactical" compromises. They close their eyes to what is secondary and has no decisive significance. But when seeing that their personal values do not fit in with the "reasonable" culture supporting the interests of both the organization and its individual members, workers have to reconsider their orientations.

Thus, the members of an organization do not stick to completely identical values, but adjust them to their own understandings and interests. Formally the same value, on passing through the crucible of a person's construal, slightly or even essentially changes its meaning. However, the distinctions come to the foreground not so often. Under normal conditions, they draw little attention and only in critical (crisis or conflict) situations when every trifle is examined nearly through a microscope leap to the eye. Then, after keen discussions or even vehement debates, the slants of workers come closer to each other, while contradictions get mitigated. Thereby, diverse individual meanings "are woven into a shared frame of reference" $[17$, p. 221]. What in the beginning seems to be incompatible and irreconcilable acquires in the end a common denominator and turns into a unity in variety, a common field of (frequently quite sensibly) differing business cultures and, eventually, becomes a source of plasticity for the organization, and a mechanism of its adapting to changing circumstances.

\subsection{Common Values: Learning or Accommodation?}

As distinct from societal, organizational culture is not learnt, but accepted (taken over). An employee not so much shares the values of his organization as accommodates himself to them and, at the same time, adjusts them to himself, eliminating the possible alienation between organizational values and his own priorities. In cases these values are not in complete tune with his notions and expectations, he normally reconciles himself to the values one way or another and sometimes even tries to "modify" (reinterpret) them so as they become closer and more understandable to him. That is why organizational culture is not in the least something strongly defined and solidified. It constantly changes, absorbing features from notable new members, and intergrinding them with the impulses from old members which, for a reason, were before disregarded. Organizational culture is a 
dynamic entity for which the communication between people is the chief condition of self-maintenance and development.

Those who prove to be not fit for the tasks leave their jobs

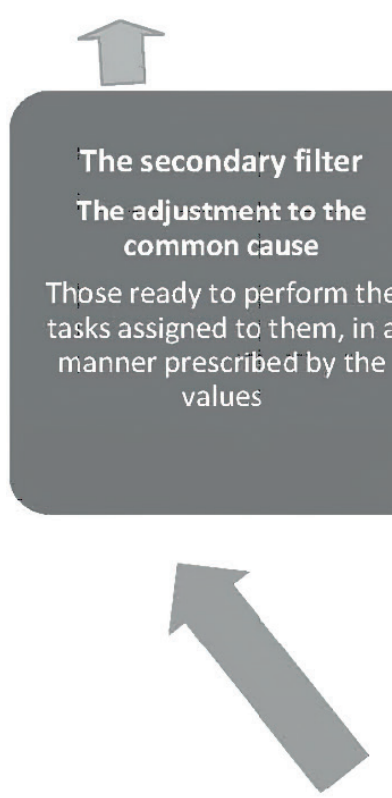

Organizational culture

\section{as a commion field of}

human relations

The joint values of those who passed the "probation" serve as the primary filter on the next turn of the helix (instead of the founders'
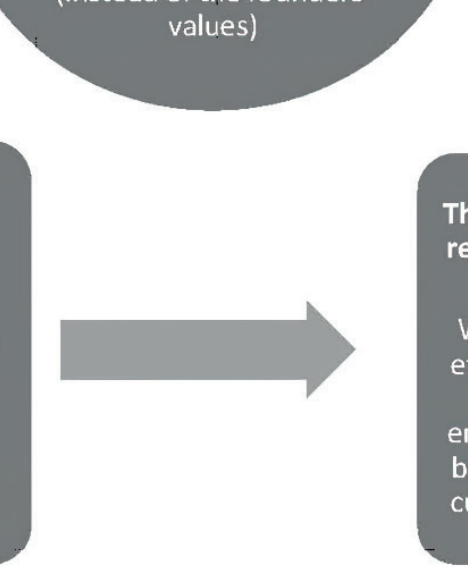

The tertiary filter

The mutual adaptation and reciprocation in the course of organiztional life

Who are able to maintain effective working relations with fellows under the enunciated business values become the bearers of the culture of the organization

The primary filter

The values of the founder(s)

Those compliant with the values of the founder(s) are admitted

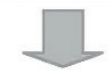

Those having not withstood the test of joint work fall away

Those with attitudes inconsistent with the founders' values drop out

People entering the organization

Figure 1. The helix of organizational culture (How a business culture gets consolidated)

Hence, without stability and long-run orientation to some established values, no strong and self-contained organizational culture is possible. But such an orientation can arise only on the condition of relatively stable employment when workers are 
deeply penetrated by the cultural dominants and pass them as a baton to newcomers. Just therefore the enterprises assigning to organizational culture the central part in shaping the relations between workers and the patterns and mechanisms of their joint activity, particularly Japanese ones, elevate the continuity of manpower to the rank of fundamental principle of business philosophy.

True, the scope of life-time employment gets smaller even in Japan. So, the amount of fixed-term workers redoubled from 1992 to 2001. By the same year, the portion of part-time employees reached nearly 23 percent. In aggregate, the nonregular labor-force constituted already one-third of those employed. Companies began to hire more outsiders, particularly in electronics and other high-tech sectors. Nevertheless, the share of regular workers was still very high -69 percent $[18$, p. $9-$ 10]. Under the hard conditions of crises in the beginning of this century when sales dropped off and all tried to find profoundly hidden reserves to survive, Japanese firms sought not to dismiss their permanent employees who were considered the bearers of tradition. Major corporations kept to their core values. So, "Toyota" had not refused to respect the principles "customer first", "investing in people", "using challenge to motivate improvement", but, to the contrary, demanded from both executives and rank and file to strictly observe them [19]. No wonder that the cultures of Japanese companies, despite some loosening, remain still rather strong.

Sure, not all workers contribute to the culture of an organization. Not everyone possesses a marked business culture, and few are able to evince their values to the extent to make the others reckon with and adopt them. But regardless of that, employees get geared and attached to the culture of their organization. Though there remain differences in both treatments and assessments of it, people get integrated into one organizational culture whose basic function consists just in making them talk if not the same language, at least its different dialects (fig. 1).

\section{Organizational Culture in Metamorphosis}

Organizational culture is in permanent change - up to radical transformations with shifts in its tendency. But they occur not because, as Schein maintains, people are "subjected" to reteaching [6, pp. $233-234]$. It is hard to believe that those with established views on organizational life and firm convictions as to how to conduct business are, for the most part, ready to confess to falling behind the times and rush to retrain themselves and learn a fundamentally new business culture. Not to mention that it remains unclear where the latter should be taken, and up with whom and what one must keep.

\subsection{Cataclysms on the Outside a Cultural Challenge}

When major shifts happen in the environment, starting with markets and finishing with law and political institutions, adaptation to which implies an essential modification or even transformation of organizational culture, not only organizations severally but their majority as an aggregate virtually concurrently revise their notions about the cultural "baggage" the "ideal" CEO must have. Neil Fligstein [20] 
has noticed that the functional background of the heads of large American companies assumed from the early $20 \mathrm{~s}$ to the late 70 s of the past century three different aspects. While in the period between the two World Wars "natives" of production were dominating, next, up to the early $60 \mathrm{~s}$, the supremacy belonged to those from sale and marketing, and afterwards, to financiers. He associates these variations with the control over organization and believes that they have been resulted from changes in strategy and structure, the amendment of antitrust laws that have promoted an increase in product-related and unrelated mergers in the postwar era, and the mimicking of firms in similar environments. In this explanation, there are, no doubt, kernels of sense. However, it does not reveal the main link in the chain extended from changes in the outside to the replacement of the generalized image of CEO. In reality, external turnabouts require significant changes in organizational culture, while renewed culture entails another mode of management which, in its turn, gets embodied in the new model of head.

At the first stage when quite capacious markets needed to be saturated with reliable goods answering the minimal demands of consumers, those responsible for the organization of works and the securing of the required parameters of output came to the fore. After the Great Depression, the belief in "fathomless" market had been broken. One could convey the mood of the time by a jocular question: "Everybody produces something, but are you able to sell it?" Naturally, at the second stage, it was sales and marketing that turned up in the spotlight. Finally, the transformation of companies into diversified conglomerates including various businesses and lines of activity, made observers perceive them as "portfolios of assets" which required competent management to yield the desired effect. This turned the financial control into the dominant of managerial vision and, respectively, enhanced its part in handling of processes and relations in organizations. No wonder that financiers much more frequently were promoted to CEO positions.

Furthermore, in $80 \mathrm{~s}$, it had been noticed that the ideal model of head changed again. Financiers were supplanted by engineers and other persons with huge technical competence. According to the company "Management practice consulting partners" which had analyzed the life experience and business bias of newly appointed CEOs, the share of those with technical or at least marketing background from 1978 to 1982 had redoubled and amounted to 50 percent of their general number [21, p. 212]. After, this tendency persisted.

Technological gaps and the intensification of competition on markets required respective remaking of organizational culture. It needed not so much to respond to emerging situations as to foresee them and, consequently, to shift the emphasis to competitive advantages and new technologies and materials, considering company "a portfolio of competences" rather than that of businesses. If the anxiety of American enterprises was before "about the low cost and high quality of Japanese imports," later they were "overwhelmed by the pace at which Japanese rivals are inventing new markets, creating new products, and enhancing them." Innovations and engineered artifacts became the heart of organizational culture of large companies, at least in knowledge-intensive and high-tech sectors. The problem lay not in technical potentialities of American business which were not a bit worse than 
those of their Japanese rivals, but just in cultural orientations. They "do not lack the technical resources to build competencies, but their top management often lacks the vision to build them and the administrative means for assembling resources spread across multiple businesses" [22, pp. 4, 10]. Hence, no small surprise that engineers as CEOs had caught on. Their task consisted just in inculcating unwonted values as a response to the challenges coming from the "outer space." For, those which could not do it were losing in competition.

\subsection{Outsiders as the Hearth of Renewal}

Without making little of those at the head of an organization, they cannot serve as the main factor of its transformation. It is hard to hand something over when the giver himself does not possess it. As Jay Barney remarks, firms without a culture proven to be successful may aim to develop the wanting attributes, but they "are generally not as successful, because the culture of the organization neither supports nor values such behavior." Conversely, those with high productivity obtained through their employees usually appreciate them, just as the obsession with "customer service and satisfaction" indubitably "reflects some of the core values" [23, p. 660]. That is to say, an organization should already have what is to be passed on. Therefore, any new cultural "seat" turns up in an organization together with new executives.

When "the CEO's personal values and personality characteristics are not aligned with the new direction of the organization" and expected shifts run counter to his vision and mindset they "will likely go unsupported" because of his being "unable or unwilling to make decisions consistent with needed changes" [8, p. 135]. Only those having essentially different attitudes and business cultures can, on getting some freedom of action, begin to purposefully transform the cultural milieu of the organization or create another one to their own templates.

Under normal conditions, the promotion of insiders, that is, bearers of the same business cultures, to CEO positions is a ready commodity. The selection of candidates within the collective is highly formalized and the power of those coming out on top entrenched. That means not in the least that outsiders are wholly out of the running, but they win very rarely. It may be said that the choice of head among people of the "same kin" is taken-for-granted in most corporations [24]. Thereby are secured both the continuity in value orientations and mutual understanding of different levels of management and areas of performance.

But when an organization is going to bring about radical changes in its culture it needs an outsider executive. He is expected to "be cognitively open-minded, with low commitment to the status quo, able to envision and consider new courses of action, and socially and interpersonally unencumbered, with low attachments to internal executives, and hence able to make major staffing changes." More than that, such an appointment in itself serves as a sign of coming turnabout and "an extraordinary measure to break with the past." If there are no "inertia-breaking forces" such as "environmental shifts, strong boards, or poor performance," that is, factors requiring major alteration of organizational culture, "not only will successors 
tend to be insiders, they will also be the insiders who are most similar to the predecessors" [25, p. $190-191,194]$. For, the demand for safeguarding the existing culture means that the head may be replaced in physical sense, but not as a bearer of culture.

\subsection{Partial Replacement of the Personnel the Core of Reformation}

Any sizeable shift in the culture of organization significantly affects personnel. As Deal and Kennedy remark, "the business of change is cultural transformation," and are blameworthy those who call for change, but ignore the "cultural issues of changing." For, new values need to become "a reality in the minds of most people throughout the company, not just the senior executives" (26, pp. 164, 23). It is easier to dismiss "inappropriate" people than to make them imbibe "unadoptable" values.

Without new blood, no cultural transformation can be successful. The unlookedfor reconfiguration in the outer environment requires cultural responses in accordance with the altered situation. But, as Joanne Martin notes, they "are too often variants of the old" [27, p. 9]. The current organizational culture as though dies, but "inexorably" resurrects like Bible's Lazarus if the personal composition of the organization remains the same. A part of its members are mostly unable, on one part, to get rid of what is deeply ingrained in them, although now needless, and on the other, to adopt the elements of another culture - useful, yet elusive - which radically differs from wonted.

Where this elementary consideration is disregarded organizations invariably fail to transform their culture. Thus, Kodak losing its leader position in the industry took a shot at preparing itself to the digital era and appointed George Fisher, an enthusiast of cultural reconstruction of the firm, as the CEO. He succeeded in reorienting several top managers, but encountered total rejection at the lower levels, including that of middle-managers with a "strong belief that Kodak meant film." Their tried and tested professional culture turned out to be an insuperable impediment to his "efforts to turn Kodak into a high-tech growth company." This "huge mass" missing the marrow of "the digital world" resisted and boycotted the new technologies, undermining the initiatives advancing digital photography, and, eventually, "jeopardized their own jobs" [28, p. 42]. No wonder: having profoundly imbibed an organizational culture and actually fused with it, they were unable to quickly switch over to another and adopt in droves the values in tune with the demands of the environment.

Not in vain, the attempts to coercively introduce into an organization a culture alien to it or to fundamentally change the existing one inevitably end in failure. When the executives of " $3 \mathrm{M}$ " decided to implement the system of quality management Six Sigma, they scarcely thought of that there was a huge mismatch between its main principles - maximization of efficiency and minimization of waste - and the firm's traditional culture which had been oriented since 40s of the past century to creative projects. Employees were used to the absence of rigidity in regulation, their activity aiming at innovativeness. That is why the new rules were taken not merely watchfully and without rapture but even with overt disapproval and 
resistance; they became a nuisance almost for all. Though some elements of the system drove their roots into the company's practice, the program as a whole failed. It had only to change the CEO, and that launched the rollback. The firm mitigated its Six Sigma policy. What fit in with the traditional culture had been retained, while the elements at variance with it, discarded [29]. They could not be implanted in the organization, as the bearers of its culture took them as alien entities.

Still more instructive is the instance of "Siemens" caught in corruption practice. Although its executives disclaimed their involvement in crimes and lumped the blame onto several unscrupulous workers, it was obvious that the organizational culture had no embedded mechanism against bribery. To put the affairs in order, the firm had in 2007, for the first time in its 160 years history, appointed to the position of CEO an outsider (bearer of another business culture), Peter Loescher. He restructured the company and made those associated with scandal be cooperative with the investigation and keep away from old manners [30, p. 173]. But had the intolerance to corruption turned into one of the firm's key values and, more importantly, a personal preference of its workers?

Soon it had been recognized that the results were at a standstill. In 2013, the policy turned about again. Instead of Loescher, Joe Kaeser, flesh and bone of "Siemens," its CFO with 33 years carrier within the firm, had been designated as CEO. In an interview to the German newspaper "Spiegel" right after his appointment, he confessed that "regardless of what I say or the mistakes I make, things are still no better than they were." The aftermath of the corruption shock had been not overcome. And it needed to "once again concentrate on our core values" [31]. But can one culturally rebuild the company and implant in it the values brooking no bribe as an instrument of achieving the organizational goals, without getting rid of those entangled in shady dealings?

Sure, a part of workers are flexible enough to easily adapt to a new tendency. Another part whose attitudes do not coincide with those of the existing culture welcome the fresh waft, because reckon on it to allow them to be on a firmer ground. And they appreciably facilitate cultural transformation. Researchers having studied a number of British companies report that the culture of quality has been established successfully in the organizations whose "employees settled comfortably into the new culture" [32, p. 640]. Such "pliant" workers appear to be the very responsive mass the new culture relies on. Where this stratum is too thin there can be no thought of cultural renewal. However, they are understandably far from being the vast majority.

A rather significant part of the personnel does not fit in with the new demands at all. The turnabout in the organization tells on them most heavily. Some leave on their own, others are dismissed on the management's initiative, the third, alienated from the business culture being propagated, nevertheless, remain in the organization, but function in a mode of "inner emigration," trying not to meddle actively in what is happening. Anyway, without an essential renewal of the personnel (the replacement of at least a weighty part of the key incumbents), particularly at the middle level of management, with bringing into the picture the bearers of the culture to be introduced, no fundamental change in culture is feasible (fig. 2). 
The emergence of renewed organizational culture

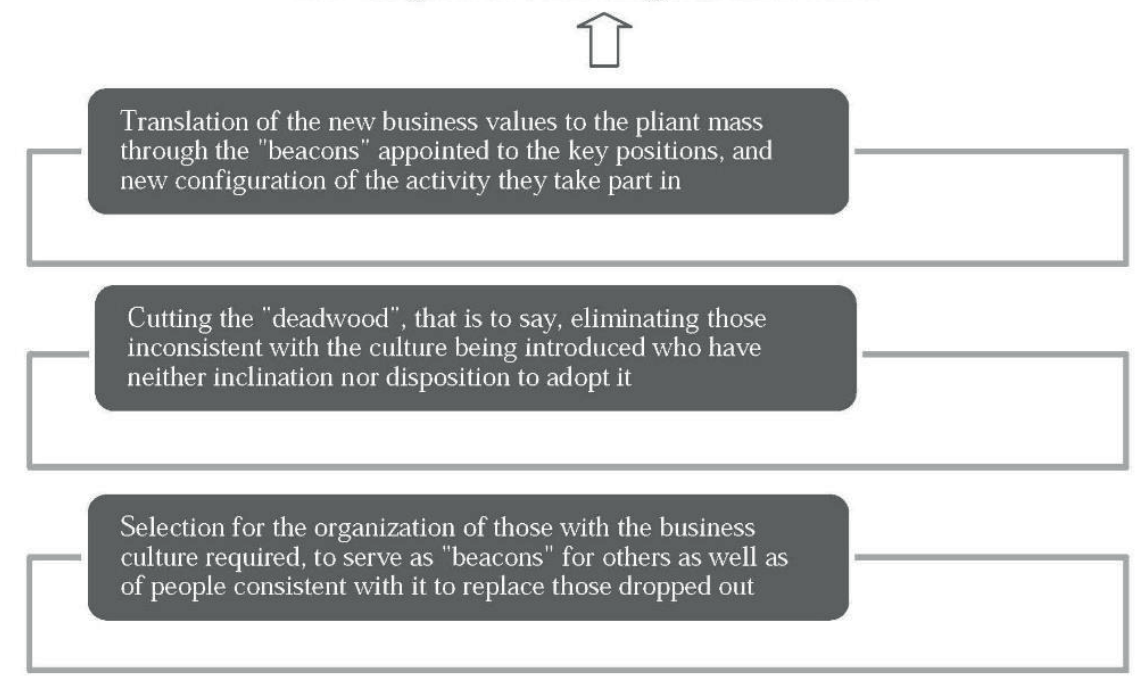

The kinds of actions the new executives undertake to transform the culture of the organization into one answering the challenges it has met with

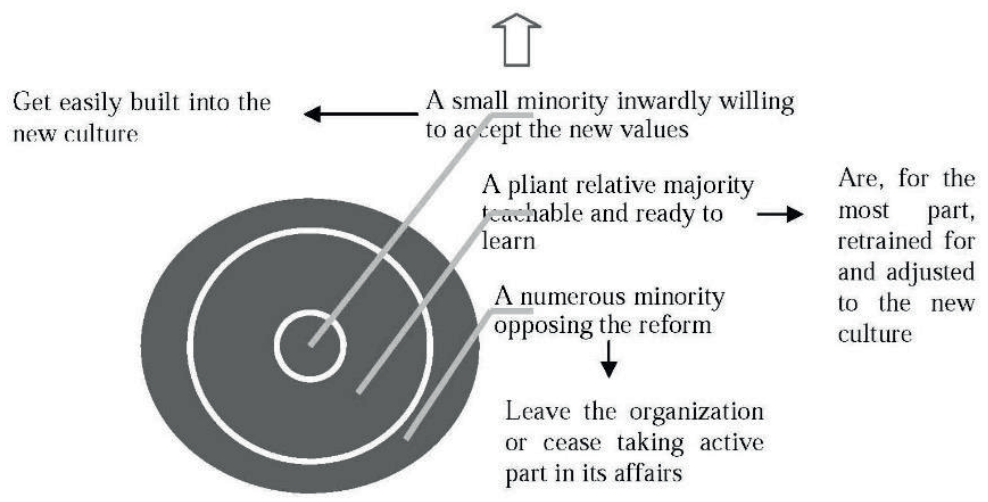

The structure of the membership as seen by the new executive(s)

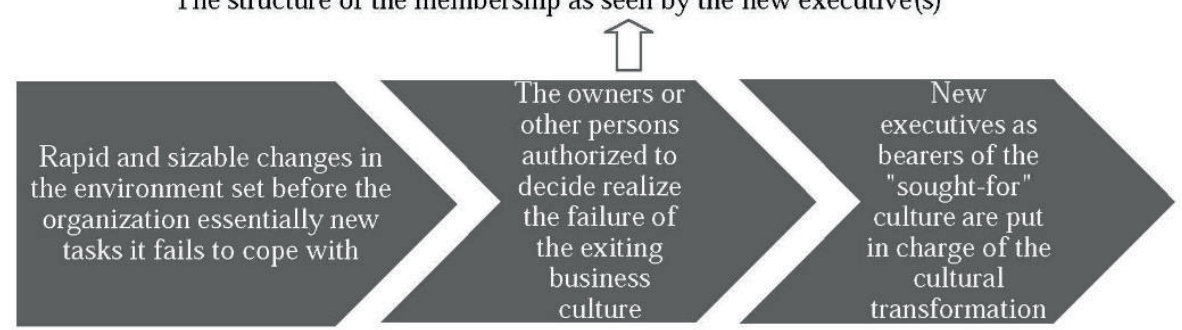

Figure 2. The pattern of cultural transformation 


\section{Cultural Split and the Ways Out}

The collision of old culture with new not always occurs when the latter comes to supersede the former. Sometimes inside an organization, a germ of another culture inconsistent with existing arises. Little by little expanding, it grows into a separate entity opposing itself to the dominant culture.

\subsection{New Culture beside Old}

At first, the new culture is not highlighted, and people take it as a peripheral offshoot or a temporary anomaly. But as this formation gets stronger and consolidates its position in the organization it turns into an alternative culture rivaling the old one. Thus a cultural split shows up which becomes a headache for the organization and not merely engenders additional conflicts and frictions but even undermines its viability.

To make sure of this it is enough to retrace the story of "Arthur Andersen." Leonard Spacek who headed it for 26 years decided once to support the experiments of Joseph Glickauf on electronic data processing, and after the first automated payroll system had been developed and set up (in 1953) at a General Electric plant, founded inside the firm an administrative system division which was meant for consulting on this sort of projects. Glickauf was a person from a whole other milieu, with quite different philosophy and business principles having little in common with Andersen's legacy. And naturally, he selected employees and built up the working relations between them, proceeding from his own understanding and preferences.

The cultural discrepancies between the units were salient from the very outset. The "bookkeepers" took the "consultants" with a fair portion of skepticism. They named the new division "Spacek's folly" and joked that its earnings were not enough to cover the expenses. However, the business philosophy and managerial abilities of Glickauf, the support lent to him by Spacek, and, more importantly, the progress of information technologies had done their work. Two decades later, the "consultants" began to secure much of incomes and got almost equal to the "accountants".

While the role of the "consultants" remained secondary few concerned about contradictions. But when the consulting unit started claiming more discretionary power and a more weighty word in making decisions the dissensions degenerated into open frictions and conflicts. In 1989, "Arthur Andersen" had to send it to market as a distinct firm under the name "Andersen Consulting." Though formal unity between the two companies was kept on the base of contractual relations under the umbrella "Andersen Worldwide," the final severance seemed to be a matter of time. In 1997, the "consultants" brought an action against the "bookkeepers" for complete separation and in 2000 it had been officially recorded - up to the removal of Andersen's name [33, pp. 231 - 233]. So the unit once set up to enlarge the company's activity and communicate to it more stability not merely failed to carry out this mission but, in the last, drove it to the verge of survival. 
Many put what has happened down to a mere conflict of interests. So, according to Andrew Crockett and his colleagues, the heart of the battle was "revenue generation and profitability" [34, p. 36]. But could these factors by themselves bring to the split?

Indeed, the statuses of the units essentially changed and the conflict for power and money acquired visible outlines. In 1989, out of 2134 partners only 586 pertained to consulting, while their unit yielded 43 percent of incomes. However, it was only a portion of the truth. Another the "bookkeepers" stood up for consisted in that the picture would be completely different if to take into consideration the contributions of all professionals working for the firm. Then, it would get clear that "bookkeepers" generated in average \$93300, while "consultants" only \$79500 [35, p. 86]. Besides, the "redistribution of revenues" occurred in nearly all firms of the kind, but it nowhere brought to so sharp consequences: the conflicting parties could relatively easily arrive at simpler and more effective solutions [34, p. 36]. Why "Arthur Andersen" found no "peaceful" way of settling the situation?

The problem of power and incomes was only the tip of the iceberg. Without belittling its acuteness and significance, another, stronger, though less conspicuous, factor lay in the heart of the conflict, which skin-popped its sides and strained the atmosphere in the firm. This has been confirmed by Duane Kullberg who headed the company in 1987 - 1989 and fulfilled the reform through which the consulting unit obtained the status of a separate company. In his words, higher reward was an important reason, "but we could have modified the compensation plan without reshaping the organization. The fact is that the change stemmed primarily from a need to position ourselves more strategically to serve a changing market" $[35, \mathrm{p} .86]$. The "consultants" had outgrown the "straitjacket" of Andersen's values and the culture established in the firm. They were sure that it should change both the work style (be more responsive to clients' demands and adapt to them more flexibly) and the business philosophy (add to its armory the principle "Profit first, at any cost"). That is why it was for them so essential to get out of the surveillance of "bookkeepers" and build up their relationships with clients independently.

\subsection{One More Head a Threat to Tradition}

The conflict in "Arthur Andersen" is often understood superficially and reductively. The responsiveness to the whims of market and the willingness to render services to clients seem to some mercenariness verging on the absence of moral standards. In 1995, even before the final "divorce," Dick Measelle, the head of the firm's audit and tax unit, heard from Matsutaro Morita, his colleague from Asahi Audit Corporation, such a diagnose of the cultural split: unlike the "accountants" guided by Samurai philosophy, the "consultants" were saturated, rather, with merchant spirit. Samurais notable for their absolute devotion and loyalty, personal dignity, call of duty, and valor could, if necessary, sacrifice their life in battle. Shame was of the key elements of their world and they did not seek profit at whatever the price - in tune with the words of Andersen who called for measuring "our contribution more by the quality of service rendered than by whether we are making a good living out 
of it" [36, p. 1]. As to merchants they, naturally, care more for profit. For the sake of it, they are ready sometimes to forsake not only their professional honor but also moral principles. But has this anything in common with reality?

The "consultants" were no less principled than the "accountants" and did not yield to them in moral standards. However, the principles and business philosophies the sides kept to were not only not congruous, but even incompatible. Both units severally were capable of surviving and prospering, but they could not get along together.

Furthermore, just the attempt of "bookkeepers" to take over, at least partly, the business culture of their more successful consultant fellows brought them to the final collapse. Seeking to implant its elements in a ground alien to it, Andersen's "heirs" had, in fact, spoiled their own culture instead of infusing new blood into it. The mishmash arose out of what could not be viable and effective. Merchant under the guise of Samurai was the worst thing one could devise.

The wish to attract clients turned into readiness to indulge them. For instance, Enron was allowed even to choose auditors. When Carl Bass, returning to the "Samurai practice", called in question some operations of the company he had been blamed for impeding the transactions and dismissed. To pander to clients "Arthur Andersen" resorted to "funky accounting, ignoring some losses and hiding others in partnerships that were off-balance-sheet" [37, pp. 6, 9]. Nevertheless, Enron burst under the burden of losses and debts and dragged with it to the bottom its auditor. But it was not Merchant that passed into nothingness on the client's heels. He continued his business under the name "Accenture," with no less success than before. Who really fell was just Samurai in the skin of Merchant.

What enabled "Arthur Andersen" to open a new market and create a source of additional incomes proved to be a delayed-action bomb. Within the organization, a completely different cultural "locus" arose which began to unfold into a selfcontained culture. Around Glickauf, gathered those holding the same views who gradually selected other workers. Together, they formed their own cultural practice fundamentally distinct from old. In $80 \mathrm{~s}$, the process had been finished in the main and required institutional legalization.

Thus, cultural splits get possible when a new head with respective authorities and charisma as well as business values and philosophy fundamentally different from "traditional" appears in the organization. If he succeeds in rallying his adherents to form a vigorous "combat unit" and makes, together with them, a go of the business they are responsible for to the interests of the organization and thereby strengthens their position in it the new business culture engendered by them becomes self-sufficient and opposes itself to old. In the issue, the organizational culture gets bifid, and the war between its parts undermines the unity of the organization and weakens and eviscerates its activity. This seems to be a kind of schizophrenia when one half of the brain orders the organism to do what is totally inadmissible for the other, and vice versa. 


\subsection{Preventing the Ruptures in Culture}

The new culture is successful if it is consonant with the demands of the environment, and the inner readiness of its bearers to take over its values not in word, but in deed. At that, as the old culture whose crown is contested by new begins to lose, it blames the latter not merely for undermining the tradition but also for unfair practices and sometimes even the breach of moral norms. Nevertheless, it gradually gets obvious that the new culture proves to be better adapted to the existing conditions and outweighs its rival. Then, the old one tries to imbibe the elements of new to recover its competitive strength. But that brings normally to not a revival, but the ruin. Since these elements are not organic to it and directly do no not fit into its framework, they get inevitably distorted and, thereby, mutilated. As a result, they not merely fail to succeed but make the culture itself nonviable.

Though intolerable, the situation is quite natural, because the alternative culture is not imposed on the organization from outside, but arises within it as a response to some vital tasks it is to perform. For this reason, cultural clearages appear to be real menace to any organization. Hence, the issue of how to avoid them acquires special importance.

There are two ways of preventing such a split in organizational culture. The first and simplest is not to allow an outstanding figure with peculiar, fundamentally different from "traditional," business culture and philosophy to take up a key and, at that, independent position in the organization and form round him a team of likeminded persons. However, such a solution is not always expedient from the practical point of view. For, it happens sometimes, as in Glickauf's case, that, thank to such a figure, the organization manages to eliminate the "bottlenecks" in its activity and improve the results obtained. To lose real and obvious advantages out of fear of possible future (sometimes very remote and even imaginative) conflicts is not the most effective approach to running the business. Therefore, if such a team poses no immediate danger to the interests of the organization and, at that, allows it to essentially raise the level of output, it is regarded as reasonable to put up with the situation. But then, one needs to be ready to potential split.

Those who have, for a reason, enabled the alternative culture to get selfcontained and oppose old may avail themselves of another means. Without waiting for acute and overt collisions between the adherents of the two confronting cultures to take place, the organization should be divided through detaching the bearers of the new culture into a separate organization capable of developing on its own and save them from the yoke of subordination to their "antagonists." If such a "divorce" takes place at a sufficiently early stage when the relations of the sides has not yet entered the phase of incompatibility it gets possible not only to deliver the both cultures from their baneful impact on each other but also to make a ground for peaceful coexistence and even fruitful cooperation in future in the capacity of independent, but "allied" entities. Otherwise they will have devoured, in an irreconcilable fight, not only each other but also the organization itself.

Some companies came to realize this as early as the last third of the past century. They widely practiced the "autonomization" of groups with business cultures 
essentially differing from that of the organization, granting them the status of independent profit centers or spin-off partnerships with discretion, within a sufficiently broad range, over what to do and how to spend money. By 1990, "Johnson and Johnson" consisted of 166 autonomous companies. "Hewlett-Packard" had about 50 separate units. The same path was taken by "AT\&T" and IBM. Large publishers created small divisions which acquired and printed books on their own. "Hitachi," "Xerox," and "3M" established new partnerships, reserving rather big stakes for themselves. Meanwhile, the reasons for that are reduced mostly to financial considerations and mercenary ends. It is brought to the fore that the heads' "compensation is linked to the unit's profits," and "risks and returns are shared between headquarters and the managers of the separate businesses" [38, p. 139]. Sure, material interests play a very important role. But it is not them that turn the scale. Just the understanding of the cultural peculiarity of emerging groups and its incompatibility with the firm's "traditional" values, and the anticipation of probable frictions and clashes are crucial to "autonomization." Due to peaceful "divorces," parent companies not merely escape destructive inner conflicts, but also retain control over prospective areas of business (fig. 3).

One more person with outstanding business culture distinct from "traditional", vested with power to man a unit or project and build a team round it engenders sooner or later another "seat" (or "hearth") of organizational culture opposing the dominant one.

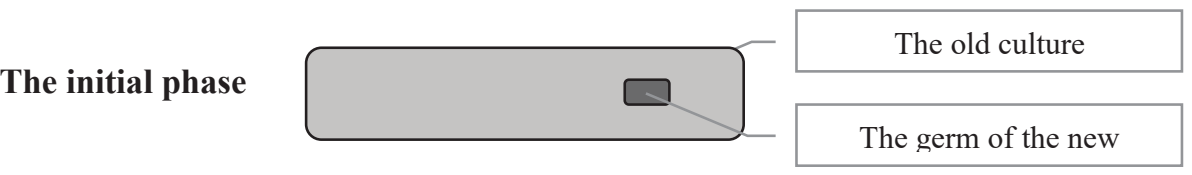

While the group the new culture ripens in remains relatively small and its influence on the organization, this culture is taken for a whimsy peripheral entity worthy of raillery rather than suppression. But as it expands and consolidates it becomes a self-sufficient force and not merely opposing the "traditional" culture, but claiming the dominance.

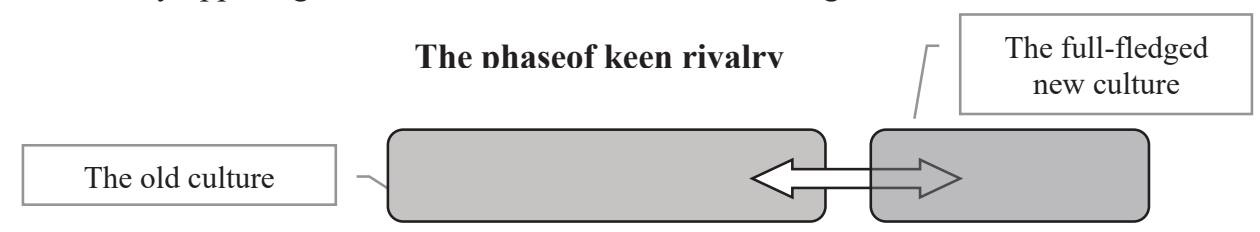

Competitive properties Advantages

Drawbacks

\section{The old culture}

- Vested with formal power

- Deeply rooted in organizational life and riding on tradition

- $\quad$ Stronger and more comprehensive

- Begins to yield to the new culture in the "turf war"

- $\quad$ Sluggish and not so much

\section{Cultures}

The new culture

- A real force competing with the old culture

- Passionary and fervent

- Ascending and evincing a positive dynamics as to both consolidation and expansion

- Mostly informal, with few officially acknowledged leverages over the 
looking ahead as clinging to the past

- Descending and waning, with comparatively small inner potential for renewal and adjustment to changing conditions organization

- Not enough ingrained in the organization's history and routine

- Still weaker in ability to influence the organizational life

The phase of keen rivalry comes in when the new culture, though still yielding to old on the whole, is strengthened enough to claim the right to be on an equal footing with it, demanding that the factual state of affairs be officially fixed. Neither side is in the position to turn the balance: numerous, but waning actual merits of old culture are countervailed with potential, but weightier virtues of new. Continuous being in such straits is deleterious for organizational culture, for as a kind of functional schizophrenia that undermines its capacity.

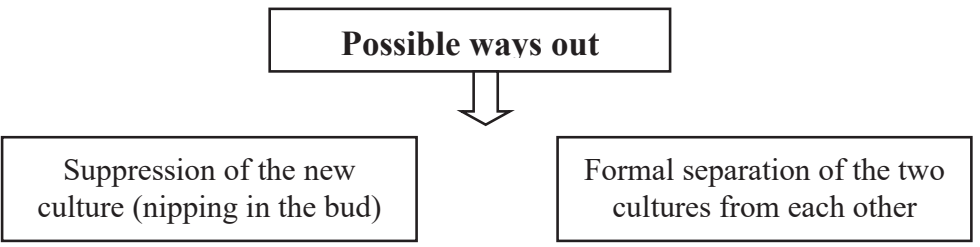

Competitive properties Merits

Demerits

Applicability

\section{Suppression}

Stamps out the sprouts of the new culture as a potential menace and radically removes the danger of cultural split

Hinders the organization in coping well with the challenges the new culture is an answer to

Suitable when the new culture emerges as an outcome of its inner perturbations, not an attempt to adjust itself to the environment

\section{Ways out}

Retains, for the organization as a whole, an effective growing culture without any direct threat to "traditional," giving the organization more flexibility and stability "Flattens" the culture of each autonomous part of the organization, what impoverishes them and lowers their adaptive potential

More complicate and less manageable, it is fit when immediate cutting ofthe new culture prevents from fulfilling some important tasks facing the organization

Figure 3. The origins of and remedies for cultural split

\section{General Conclusions}

The unity of organizational culture is secured, first and foremost, by the selection of "right" personnel. The common cause the workers are to be adjusted to gradually glosses over the discrepancies in their attitudes towards it. Moreover, it makes them not attach primary importance to most of varieties still remaining. That is why even the values not to their liking arouse in them frequently little opposition.

In the course of joint activity, workers "rub together," get used to others' mindsets, and "correct" their own to avoid collisions and conflicts. They come closer and get adapted to each other, while their notions of what and how to do, primordially too diverse, begin to overlap or even coincide. This imparts a certain measure of homogeneity to the business cultures of individuals. But no employee shares the values of his organization in the sense of assimilating, or adopting them 
unreservedly. Rather, each accommodates himself to the values as well as adjusts them to himself, what essentially mitigates the completely not removable strain in relations both among workers and between their personal and organizational values.

The germ of the culture of any organization is the business culture of its founder(s) or first head(s). It sets the tone of development in the course of which acquires more comprehensive contents and, gradually absorbing the compatible impulses coming from other notable members, unfolds and turns into a full-fledged organizational culture. The bits of a new culture begin to take shape with the coming of executives having different visions and business cultures and wanting to transform the cultural milieu or create another to their own templates. Such leaders try to replace the existing values with their "own" or raise the sprouts of a different culture somewhat away from old, the chances of success being determined largely by the consonance of new values with the needs of the organization, and the inner readiness of its personnel to take them over.

No attempt to coercively transform an existing culture or introduce into an organization a culture alien to it can be crowned with success. Its people may be divided into three main groups: 1) a small minority inwardly willing to accept the alternative values because of taking old critically and wanting to change them;2) the pliant relative majority not enthusiastic over the new culture, but teachable and ready to participate in alterations to the organization's and their own benefits; and 3) a rather numerous minority opposing the reformers (in view of commitment to the old culture or reluctance to get engaged in changes). To overcome the "strength of materials" the head needs reliable pivots, that is to say, a number of like-minded persons on the key positions coming, as a rule, from the outside as bearers of the culture to be introduced and serving as "beacons" (models to follow). Though comparatively few, they carry much weight. Besides, a body of people enters the organization to replace those leaving it because of their incompatibility with its proclaimed business values. Most of newcomers remain in the organization and take part in working out the new culture. It gets gradually imparted to the pliant mass in accord with the "helix mechanism." As to the opponents their majority leave the organization or, remaining there, imitate loyalty, only few of them joining in the new culture with time.

When another cultural "seat" inconsistent with existing emerges in the organization and, gradually expanding, grows into a separate entity opposing itself to the traditional culture, the divergence in values turns, at last, into a cultural split. An organization with bifid culture resembles a schizophrenic making inconsistent and conflicting decisions and, therefore, normally not achieving the results intended. Such an effect can be recovered in two ways. The first implies forbidding big figures to make around them self-contained business cultures, what is sometimes not merely non-efficient, but even harmful to the tasks being performed, while the second, the separation of the bearers of the new culture (before its confrontation with old has turned into a menace to the organization) into an autonomous division not accountable to their "old" opponents. That allows the organization to get, instead of self-destruction, an opportunity for self-diversification and strengthening its position in the external environment. 


\section{References}

[1] E. Jaques. The Changing Culture of a Factory: A Study of Authority and Participation in an Industrial Setting. London: Routledge; New York: Dryden Press, 1951.

[2] T. Parsons. Structure and Process in Modern Societies. Glencoe, IL: Free Press, 1960.

[3] T.Parsons. On Institutions and Social Evolution: Selected Writings. Chicago, IL: The University of Chicago Press, 1985.

[4] S. Giorgi, C. Lockwood, and M. A. Glynn. "The Many Faces of Culture: Making Sense of 30 Years of Research on Culture in Organization Studies," Academy of Management Annals, vol. 9, no.1, pp. 1 - 54, 2015.

[5] G. Hofstede. "Dimensions Do Not Exist: A Reply to Brendan McSweeney," Human Relations, vol. 55, no.11, pp. 1355-1361, 2002.

[6] E. H. Schein. "The Role of the Founder in Creating Organizational Culture.” Family Business Review, vol. 8, no. 3, pp. 221-238, 1995.

[7] Arthur Andersen and Company. The First Fifty Years. Chicago,IL: Arthur Andersen, 1963.

[8] T. R. Giberson, Ch. J. Resick, M. W. Dickson, J. K. Mitchelson, K. R. Randall, and M. A. Clark. "Leadership and Organizational Culture: Linking CEO Characteristics to Cultural Values," Journal of Business and Psychology, vol. 24, no. 2, pp. 123-137, 2009.

[9] J. K. Liker and D. Meier. The Toyota Way Fieldbook: A Practical Guide for Implementing Toyota's 4 Ps. New York, NY: McGraw-Hill, 2006.

[10] Y-T. Lee, B. S. Reiche, and D. Song. "How Do Newcomers Fit In: The Dynamics Between Person - Environment Fit and Social Capital across Cultures," International Journal of Cross-cultural Management, vol. 10, no. 2, pp. 153 - 174, 2010.

[11] J. P.Meyer, T. D. Hecht, H. Gill, and L. Toplonytsky, "Person Organization (Culture) Fit and Employee Commitment under Conditions of Organizational Change: A Longitudinal Study," Journal of Vocational Behavior, vol. 76, no. 3, pp. $458-473,2010$.

[12] A. E. Petrosyan, "Regaining the Soul Lost (The Limits of Depersonalization in Organizational Management)," Philosophy of Management, vol. 18, no. 2, pp. 131-155, 2019.

[13] E.Lander and J. Liker, "The Toyota Production System and Art: Making Highly Customized and Creative Products the Toyota way," International Journal of Production Research, vol. 45, no. 16, pp. 3681-3698, 2007. 
[14] A. E. Petrosyan, "Whirling in between the Personal and the Impersonal: The Quest for the Marrow of Organizational Goals, and the Lessons to Be Drawn Thence," Journal of Management History, vol. 25, no. 2, pp. 257-284, 2019.

[15] D. Mehri, “The Darker Side of Lean: An Insider's Perspective on the Realities of the Toyota Production System," Academy of Management Perspectives, vol. 20, no. 2, pp. 21-42, 2006.

[16] S. G. Rogelberg, C. Scott, and J. Kello, "The Science and Fiction of Meetings," MIT Sloan Management Review, vol. 48, no. 2, pp. 17 - 21, 2007

[17] A. Saka, "The Cross-national Diffusion of Work Systems: Translation of Japanese Operations in the UK," Organization Studies, vol. 25, no. 2, pp. 209-228, 2004.

[18] T. Hanami, "The Changing Labor Market, Industrial Relations and Labor Policy." Japan Labor Review, vol. 1, no. 1, pp. 4-16, 2004.

[19] G. Metcalfe, Toyota Under Fire: An interview with Jeffrey K. Liker, July, 2011, http://www.emeraldgrouppublishing.com/learning/management_thinking/i nterviews/liker.htm?PHPSESSID=ucqm401n6q81s7h4n4f6t8ds 55 .

[20] N. Fligstein, "The Intraorganizational Power Struggle: Rise of Finance Personnel to Top Leadership in Large Corporations, 1919 - 1979," American Sociological Review, vol. 52, no. 1, pp. 44-58, 1987.

[21] R. Foster, Innovation: The Attacker's Advantage. Moscow: Progress, 1987.

[22] C. K. Prahalad and G. Hamel, "The Core Competence of the Corporation." Harvard Business Review, May-June, pp. 2-14, 1990.

[23] J. B. Barney, "Organizational Culture: Can It Be a Source of Sustained Competitive Advantage?" Academy of Management Review, vol.11, no. 3, pp. $656-665,1986$.

[24] W. Ocasio and H. Kim, "The Circulation of Corporate Control: Selection of Functional Backgrounds of New CEOs in Large U. S. Manufacturing Firms, 1981-1992," Administrative Science Quarterly, vol. 44, no. 3, pp. $532-562,1999$.

[25] S. Finkelstein, D. C. Hambrick, and A. A. Cannella. Strategic Leadership: Theory and Research on Executives, Top Management Teams, and Boards. Oxford: Oxford University Press, 2009.

[26] T. E. Deal and A. A. Kennedy, Corporate Cultures: The Rites and Rituals of Corporate Life. Reading, MA: Addison-Wesley,1982.

[27] J. Martin, Organizational Culture: Mapping the Terrain. Thousand Oaks, CA: Sage, 2002. 
[28] S. Habersang, J. Küberling-Jost, M. Reihlen, and Ch. Seckler,“ A Process Perspective on Organizational Failure: A Qualitative Meta-Analysis," Journal of Management Studies, vol. 56, no. 1, pp. 19 - 56, 2018.

[29] A. Canato, D. Ravasi, and N. Phillips, “Coerced Practice Implementation in Cases of Low Cultural Fit: Cultural Change and Practice Adaptation during the Implementation of Six Sigma at 3M," Academy of Management Journal, vol. 56, no. 6, pp. 1724-1753, 2013.

[30] J. Pfister, Managing Organizational Culture for Effective Internal Control: From Practice to Theory. Berlin; Heidelberg: Physica-Verlag, 2009.

[31] Siemens CEO, ““We Need to See Calm Restored.” After the recent turbulence at Siemens, the company's new CEO, Joe Kaeser, tells SPIEGEL why the company needs a fresh start," Spiegel Online International, August, 07, 2013.

[32] D. Adebanjo, and D. Kehoe, "An Investigation of Quality Culture Development in UK Industry," International Journal of Operations and Production Management, vol. 19, no. 7, pp. 633-650, 1999.

[33] P. M. Clikeman, Called to Account: Financial Frauds that Shaped the Accounting Profession. New York, NY: Routledge, 2013.

[34] A. Crockett, T. Harris, F. C. Mishkin, and E. N. White. Conflicts of Interests in the Financial Services Industry: What Should We Do about Them? Geneva: ICMB, 2003.

[35] S. E.Squires, C. J. Smith, L. McDougall, and W. R. Yeack. Inside Arthur Andersen: Shifting Values, Unexpected Consequences. Upper Saddle River, NJ: Prentice-Hall, 2003.

[36] D. Measelle, "Merchant or Samurai?" Chicago Tribune, September 1, 2002, www.chicagotribune.com/business/showcase/chi020901measele.story.

[37] D. Alexander, G. Burns, R. Manor, F. McRoberts, and E. A. Torriero, "Ties to Enron Blinded Andersen," Chicago Tribune, September, 3, pp. $1-$ 13, 2002.

[38] R. B. Reich, "The Work of Nations," In Social Theory: A Reader. Vol. I. The Formative Years. Ed. by R. Garner, pp. 136 - 144.Toronto: University of Toronto Press, 2010. 